\title{
Perbandingan Kinerja Multifactor Evaluation Process (MFEP) dengan Analytic Hierarchy Process (AHP) dalam Menentukan Mutasi Karyawan (Studi Kasus pada PT Sumber Alfaria Trijaya, Tbk Departement Information Technology)
}

\author{
Agus Komarudin, Reni Permata Sari, Aliy Hafiz \\ Fakultas Sains dan Teknologi, Universitas Nahdlatul Ulama Lampung \\ Jln. Lintas Pantai Timur Sumatera Kabupaten Lampung Timur 34193 Telp. (0725) 7631380 \\ aguskomarudin689@gmail.com
}

Intisari - Perkembangan dari sistem pengambilan keputusan saat ini terus meningkat, pada penelitian sebelumnya penulis hanya menggunakan salah satu metode, upaya meningkatkan kinerja dan pelaksanaan tugas bagi karyawan, dalam meningkatkan motivasi bagi karyawan, salah satu cara yang ditempuh dalam langkah nyata adalah mutasi karyawan sesuai dengan kriteria yang telah ditentukan antara lain absensi, mengisi joblist, kunjungan sesuai RPIT, disiplin, kerjasama team, inovasi, dan kominmen terhadap perusahaan dimana penulis akan menggunakan dua metode sistem pengambilan keputusan untuk mendapatkan perbandingan. Pada PT Sumber Alfaria Trijaya, Tbk Departement IT terbagi menjadi 2 Divisi, yaitu IT Office Support dan IT Store Support, IT Office Support bertugas memonitor dan maintenance semua aplikasi yang berjalan di Office serta DC, sedangkan IT Store Support bertugas memonitor dan maintenance semua aplikasi yang berjalan di Store/Toko. Pada tahun 2016 Manager dituntut oleh manajemen untuk mengurangi staff IT, baik pada IT Office Support maupun IT Store Support. IT Store Support 9 orang, IT Office Support 4 orang. Berdasarkan peraturan baru IT Store Support membutuhkan karyawan berdasarkan rasio 1:50 yaitu 1 orang 50 toko, jumlah toko saat ini 260 toko, jadi $260 / 50=5,2$ jadi seharusnya hanya 5-6 orang untuk jumlah IT Store Support. Sedangkan IT Office Support Shift kerja dengan 3 Shift membutuhkan minimal 5 orang. Manager harus menentukan karyawan dengan jabatan IT Store Support akan di Mutasi 2 orang dan 1 orang pindah Divisi. Beberapa metode yang digunakan dalam SPK diantaranya adalah metode Multi Factor Evalution Process (MFEP) dan Analytic Hierarchy Process (AHP). Dengan adanya dua metode tersebut penulis ingin mengetahui metode manakah yang cocok untuk menentukan Mutasi Karyawan.

Kata kunci - AHP, MFEP, Mutasi, Karyawan, Dua Metode

Abstract - The development of the current decision-making system continues to increase, in previous studies the author only uses one method, efforts to improve performance and implementation of tasks for employees, in increasing motivation for employees, one way that is taken in real steps is employee mutation according to the criteria have been determined, among others, attendance, filling in job lists, visits according to the RPIT, discipline, teamwork, innovation, and commitment to the company where the author will use two decisionmaking system methods to get a comparison. At PT Sumber Alfaria Trijaya, Tbk, the IT Department is divided into 2 Divisions, namely IT Office Support and IT Store Support, IT Office Support is in charge of monitoring and maintenance of all applications running in the Office and DC, while IT Store Support is in charge of monitoring and maintenance of all applications walk in the Store / Shop. In 2016 the Manager was demanded by management to reduce IT staff, both in IT Office Support and IT Store Support. IT Store Support 9 people, IT Office Support 4 people. Based on the new regulations, IT Store Support requires employees based on a 1:50 ratio, namely 1 person 50 stores, the number of stores is currently 260 stores, so 260/50 $=5.2$ so it should only be 5-6 people for the number of IT Store Support. While IT Office Support Shift working with 3 shifts requires a minimum of 5 people. The manager must determine which employees with the IT Store Support position will transfer 2 people and 1 person move the Division. Some of the methods used in the DSS include the Multi Factor Evaluation Process (MFEP) and Analytic Hierarchy Process (AHP). With these two methods, the writer wants to know which method is suitable for determining employee mutations.

Keywords - AHP, MFEP, Mutasi, Karyawan, Dua Metode 


\section{PENDAHULUAN}

Meningkatkan upaya kinerja dan pelaksanaan tugas bagi karyawan, dalam meningkatkan motivasi dan perasaan puas bagi karyawan, salah satu cara yang ditempuh dalam langkah nyata adalah mutasi karyawan sesuai persyaratan-persyaratan yang telah ditentukan antara lain kemampuan karyawan, perilaku karyawan, disiplin karyawan. Bila mutasi karyawan dilakukan secara baik dan terbuka, maka karyawan akan puas dan timbul persaingan positif dalam meningkat kinerja masing-masing karyawan, dan sebaliknya bila mutasi karyawan dilakukan secara tidak profesional dan tidak terbuka, maka motivasi karyawan akan turun dan menimbulkan kinerja karyawan yang buruk.

Pada PT Sumber Alfaria Trijaya, Tbk Departement IT terbagi menjadi 2 Divisi, yaitu IT Office Support dan IT Store Support, IT Office Support bertugas memonitor dan maintenance semua aplikasi yang berjalan di Office serta DC, sedangkan IT Store Support bertugas memonitor dan maintenance semua aplikasi yang berjalan di Store/Toko. Pada tahun 2016 Manager dituntut oleh manajemen untuk mengurangi staff IT, baik pada IT Office Support maupun IT Store Support. IT Store Support 9 orang, IT Office Support 4 orang.

Berdasarkan peraturan baru IT Store Support membutuhkan karyawan berdasarkan rasio 1:50 yaitu 1 orang 50 toko, jumlah toko saat ini 260 toko, jadi $260 / 50=5,2$ jadi seharusnya hanya 5-6 orang untuk jumlah IT Store Support. Sedangkan IT Office Support Shift kerja dengan 3 Shift membutuhkan minimal 5 orang. Manager harus menentukan karyawan dengan jabatan IT Store Support akan di Mutasi 2 orang dan 1 orang pindah Divisi. Sistem Pendukung Keputusan (SPK) adalah sistem berbasis komputer yang mampu memecahkan masalah-masalah yang tidak terstruktur.

Beberapa metode yang digunakan dalam SPK diantaranya adalah metode Multi Factor Evalution Process (MFEP) dan Analytic Hierarchy Process (AHP). Multifactor Evaluation Process (MFEP) merupakan model pengambilan keputusan yang menggunakan pendekatan kolektif dari proses pengambilan keputusannya, AHP adalah suatu metode yang sederhana dan fleksibel yang menampung kreativitas dalam ancangannya terhadap suatu masalah. Dengan adanya dua metode tersebut penulis ingin mengetahui metode manakah yang cocok untuk menentukan Mutasi Karyawan [4]. Berdasarkan pemaparan tersebut, maka dalam penelitian ini penulis mengambil judul Perbandingan Kinerja Multifactor Evaluation Process (MFEP) dengan Analytic Hierarchy Process (AHP) dalam menentukan mutasi karyawan (Studi Kasus pada PT Sumber Alfaria Trijaya, Tbk Departement Information Technology).

\section{LANDASAN TEORI}

Sistem Pendukung Keputusan (SPK) Adalah Sistem Berbasis Komputer Interaktif, Yang Mengambil Para Keputusan Untuk Menggunakan Data Dan Berbagai Model Untuk Memecahkan Masalah Yang Tidak Terstruktur. Sistem Pendukung Keputusan Memadukan Sumber Daya Intelektual Dari Individu Dengan Kepastian Komputer Untuk Meninggalkan Kualitas Keputusan.

Menurut Alter (2002) yang dikutip dalam buku konsep dan aplikasi sistem pendukung keputusan, Kusrini (2007) bahwa sistem pendukung keputusan merupakan sistem informasi interaktif yang menyediakan informasi, pemodelan dan pemanipulasian data. Sistem itu digunakan untuk membantu pengambilan keputusan dalam situasi yang semiterstruktur dan situasi yang terstruktur, dimana Tak seorangpun tahu secara pasti bagaimana keputusan seharusnya dibuat [1].

Multifactor Evaluation Process (MFEP) merupakan model pengambilan keputusan yang menggunakan pendekatan kolektif dari proses pengambilan keputusannya (Render dan Stair, 2002) [2].

Analytical Hierarchy Process (AHP) Menurut Saaty (1986) Analytical Hierarchy Process (AHP) yang dikutip dalam buku Teknik dan Aplikasi Pengambilan Keputusan Kriteria Majemuk , Marimin (2004) AHP adalah suatu metode yang sederhana dan fleksibel yang menampung kreativitas dalam ancangannya terhadap suatu masalah [3]. 


\section{METODOLOGI PENELITIAN}

\section{A. Tempat dan Waktu Penelitian}

Objek penelitian adalah PT Sumber Alfaria Trijaya, Tbk departement Information Technology. Terletak Jl. Tembesu No. 10 By Pass Soekarno Hatta (Kompleks Gudang Bulog) Campang Raya, Tanjung Karang Timur, Bandar Lampung. Dalam melaksanakan tahapan penelitian, peneliti merencakan waktu penelitian dari bulan Juli sampai September 2016.

\section{B. Kriteria Tolak Ukur}

Kriteria yang digunakan sebagai tolak ukur dalam menentukan karyawan yang berkompeten.

1. Absensi

2. Mengisi Joblist

3. Kunjungan Sesuai RPIT

4. Disiplin

5. Kerjasama Team

6. Inovasi

7. Komitmen Perusahaan

C. Perhitungan MFEP

1) Nilai Bobot Untuk Faktor

Tabel 1. Nilai Bobot Untuk Faktor

\begin{tabular}{|c|c|}
\hline Faktor & Nilai Bobot \\
\hline Faktor 1 & $\mathrm{a}$ \\
\hline Faktor 2 & $\mathrm{~b}$ \\
\hline Faktor 3 & $\mathrm{c}$ \\
\hline
\end{tabular}

2) Evaluasi Faktor

Tabel 2. Evaluasi Faktor

\begin{tabular}{|l|c|c|c|}
\hline Faktor & $\begin{array}{c}\text { Karyawan } \\
1\end{array}$ & $\begin{array}{c}\text { Karyawan } \\
2\end{array}$ & $\begin{array}{c}\text { Karyawan } \\
3\end{array}$ \\
\hline Faktor 1 & $\mathrm{~d}$ & $\mathrm{~d}$ & $\mathrm{~d}$ \\
\hline Faktor 2 & $\mathrm{e}$ & $\mathrm{e}$ & $\mathrm{e}$ \\
\hline Faktor 3 & $\mathrm{f}$ & $\mathrm{f}$ & $\mathrm{f}$ \\
\hline
\end{tabular}

Setiap Karyawan yang akan diseleksi mempunyai sebuah nilai evaluasi bagi faktorfaktor yang menjadi pertimbangannya, dan kemudian nilai faktor tersebut dikalikan dengan faktor evaluasi dan dijumlahkan untuk mendapatkan total nilai evaluasi untuk setiap tahapan seleksi. Berikut tabel hasil total evaluasi:
3) Evaluasi Untuk Karyawan

Tabel 3. Evaluasi Karyawan 1

\begin{tabular}{|l|r|r|r|r|}
\hline \multicolumn{5}{|c|}{ Karyawan 1 } \\
\hline Faktor & $\begin{array}{c}\text { Bobot } \\
\text { Faktor }\end{array}$ & Kali & $\begin{array}{c}\text { Evaluasi } \\
\text { Faktor }\end{array}$ & $\begin{array}{c}\text { Bobot } \\
\text { Evaluasi }\end{array}$ \\
\hline Faktor 1 & $\mathrm{a}$ & $\mathrm{x}$ & $\mathrm{d}$ & $\mathrm{x}$ \\
\hline Faktor 2 & $\mathrm{b}$ & $\mathrm{x}$ & $\mathrm{e}$ & $\mathrm{y}$ \\
\hline Faktor 3 & $\mathrm{c}$ & $\mathrm{x}$ & & $\mathrm{f}$ \\
\hline Total & 1 & & & $\mathrm{z}$ \\
\hline
\end{tabular}

Tabel 4. Hasil Total Evaluasi

\begin{tabular}{|c|c|c|}
\hline No & Nama Karyawan & $\begin{array}{c}\text { Total } \\
\text { Bobot } \\
\text { Evaluasi }\end{array}$ \\
\hline 1 & Karyawan 1 & Sum(1) \\
\hline 2 & Karyawan 2 & Sum(2) \\
\hline 3 & Karyawan 3 & Sum(3) \\
\hline
\end{tabular}

Metode MFEP menentukan bahwa alternatif dengan nilai tertinggi adalah solusi terbaik berdasarkan kriteria yang telah dipilih, dari beberapa karyawan dipilih peringkat teratas dari hasil total bobot evaluasi, karena dalam kasus ini penulis menginginkan mutasi, maka diambil peringkat terbawah [6].Dari hasil peringkat teratas terdapat peringkat terakhir. Ini dapat dijadikan acuan untuk mutasi karyawan ke Divisi lain yaitu IT Office Support atau mutasi ke Branch lain.

\section{Perhitungan AHP}

1) Pair Comparation Matrix Kriteria Tabel 5. Pair Comparation Matrix Kriteria

\begin{tabular}{|l|c|c|c|r|}
\hline Kriteria & $\begin{array}{c}\text { Faktor } \\
1\end{array}$ & $\begin{array}{c}\text { Faktor } \\
2\end{array}$ & $\begin{array}{c}\text { Faktor } \\
3\end{array}$ & $\begin{array}{l}\text { Priority } \\
\text { Vector }\end{array}$ \\
\hline Faktor 1 & $\mathrm{x} 1$ & $\mathrm{a}$ & $\mathrm{b}$ & $\mathrm{PV} 1$ \\
\hline Faktor 2 & $\mathrm{x} 1 / \mathrm{a}$ & $\mathrm{x} 2$ & $\mathrm{c}$ & $\mathrm{PV} 2$ \\
\hline Faktor 3 & $\mathrm{x} 1 / \mathrm{b}$ & $\mathrm{x} 2 / \mathrm{c}$ & $\mathrm{x} 3$ & $\mathrm{PV} 3$ \\
\hline Jumlah & Sum(1) & $\mathrm{Sum}(2)$ & $\mathrm{Sum}(3)$ & $\begin{array}{r}\text { Sum(P } \\
\mathrm{V})\end{array}$ \\
\hline Principle Eigen Value & $\mathrm{PEV}$ \\
\hline \multicolumn{3}{|l|}{ Consistency Index } & $\mathrm{CI}$ \\
\hline \multicolumn{2}{|l}{ Consistency Ratio } & $\mathrm{CR}$ \\
\hline
\end{tabular}

PV1 $=(x 1 / \operatorname{sum}(1)+a / \operatorname{sum}(2)+b / \operatorname{sum}(3)) / J u m($ Kriteria) PV2 $=((x 1 / a) / \operatorname{sum}(1)+x 2 / \operatorname{sum}(2)+\mathrm{c} / \operatorname{sum}(3)) /$ Jum(Kriteria) 
PV3 $=((\mathrm{x} 1 / \mathrm{b}) / \operatorname{sum}(1)+(\mathrm{x} 2 / \mathrm{c}) / \mathrm{sum}(2)+\times 3 / \mathrm{su}$ $\mathrm{m}(3)) / \mathrm{Jum}($ Kriteria)

$\mathrm{PEV}=\operatorname{sum}(1) * \mathrm{PV} 1+\operatorname{sum}(2) * \mathrm{PV} 2+\operatorname{sum}(3) * \mathrm{P}$

V 3

$\mathrm{CI}=(\mathrm{PEV}-\mathrm{Jum}($ Kriteria)$) /(J u m($ Kriteria $)-1))$

$\mathrm{CR}=\mathrm{CI} /$ Index Random

Pair Comparation Matrix Faktor 1

Tabel 6. Pair Comparation Matrix Faktor 1

\begin{tabular}{|c|c|c|c|c|}
\hline $\begin{array}{c}\text { Faktor } \\
1 \\
\end{array}$ & $\begin{array}{c}\text { Karyawa } \\
\text { n } 1\end{array}$ & $\begin{array}{c}\text { Karyawa } \\
\text { n } 2 \\
\end{array}$ & $\begin{array}{c}\text { Karyaw } \\
\text { an } 3 \\
\end{array}$ & $\begin{array}{l}\text { Priority } \\
\text { Vector } \\
\end{array}$ \\
\hline $\begin{array}{l}\text { Karya } \\
\text { wan 1 }\end{array}$ & $\mathrm{x} 1$ & 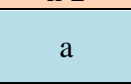 & . & PV 1 \\
\hline $\begin{array}{l}\text { Karya } \\
\text { wan } 2 \\
\end{array}$ & $\mathrm{x} 1 / \mathrm{a}$ & $\mathrm{x} 2$ & $\mathrm{c}$ & PV 2 \\
\hline $\begin{array}{l}\text { Karya } \\
\text { wan } 3 \\
\end{array}$ & $\mathrm{x} 1 / \mathrm{b}$ & $\mathrm{x} 2 / \mathrm{c}$ & $\mathrm{x} 3$ & PV 3 \\
\hline Jumlah & Sum(1) & $\operatorname{Sum}(2)$ & Sum(3) & $\begin{array}{r}\text { Sum(P } \\
\mathrm{V}) \\
\end{array}$ \\
\hline \multicolumn{4}{|c|}{ Principle Eigen Value } & PEV \\
\hline \multicolumn{4}{|c|}{ Consistency Index } & $\mathrm{CI}$ \\
\hline \multicolumn{4}{|c|}{ Consistency Ratio } & CR \\
\hline
\end{tabular}

PV1 $=(x 1 / \operatorname{sum}(1)+a / \operatorname{sum}(2)+b / \operatorname{sum}(3)) / \mathrm{Jum}(\mathrm{K}$ riteria)

PV2 $=((x 1 / a) / \operatorname{sum}(1)+x 2 / \operatorname{sum}(2)+\mathrm{c} / \operatorname{sum}(3)) / \mathrm{Ju}$ $\mathrm{m}($ Kriteria)

PV3 $=((x 1 / b) / \operatorname{sum}(1)+(x 2 / c) / \operatorname{sum}(2)+\times 3 /$ sum (

3) $) / \operatorname{Jum}($ Kriteria)

$\mathrm{PEV}=\operatorname{sum}(1) * \mathrm{PV} 1+\operatorname{sum}(2) * \mathrm{PV}$

$2+\operatorname{sum}(3) * P V ~ 3$

$\mathrm{CI}=(\mathrm{PEV}-\mathrm{Jum}($ Kriteria)$) /(J u m($ Kriteria $)-1))$

$\mathrm{CR}=\mathrm{CI} /$ Index Random

Overall Composite Weight

Tabel 7. Overall Composite Weight

\begin{tabular}{|l|l|l|l|l|}
\cline { 2 - 5 } \multicolumn{1}{c|}{} & Weight & $\begin{array}{l}\text { Karyawan } \\
1\end{array}$ & $\begin{array}{l}\text { Karyawan } \\
2\end{array}$ & $\begin{array}{l}\text { Karyaw } \\
\text { an 3 }\end{array}$ \\
\hline $\begin{array}{l}\text { Faktor } \\
\begin{array}{l}\text { Faktor } \\
2\end{array}\end{array}$ & $\begin{array}{l}\text { PV } \\
\text { Faktor1 }\end{array}$ & $\begin{array}{l}\text { PV K1 } \\
\text { Faktor1 }\end{array}$ & $\begin{array}{l}\text { PV K2 } \\
\text { Faktor 1 }\end{array}$ & $\begin{array}{l}\text { PV K3 } \\
\text { Faktor } \\
1\end{array}$ \\
\hline $\begin{array}{l}\text { Faktor } \\
3\end{array}$ & Faktor2 & $\begin{array}{l}\text { PV K1 } \\
\text { Faktor2 }\end{array}$ & $\begin{array}{l}\text { PV K2 } \\
\text { Faktor 2 }\end{array}$ & $\begin{array}{l}\text { PV K3 } \\
\text { Faktor } \\
2\end{array}$ \\
\hline $\begin{array}{l}\text { Compo } \\
\text { site } \\
\text { Weight }\end{array}$ & Faktor3 & PV K1 & FV K2 & $\begin{array}{l}\text { PV K3 } \\
\text { Faktor } \\
3\end{array}$ \\
\hline
\end{tabular}

CW 1=(PV Faktor1*PV K1 Faktor1) $+(\mathrm{PV}$

Faktor 2*PV K1 Faktor2) + (PV Faktor3*PV

K1 Faktor3)

CW $2=($ PV Faktor $1 *$ PV K2 Faktor 1$)+($ PV

Faktor2*PV K2 Faktor2) + (PV Faktor3*PV

K2 Faktor3)
CW 3=(PV Faktor1*PV K3 Faktor1 $)+($ PV

Faktor2*PV K3 Faktor2) + (PV Faktor3*PV

K3 Faktor3)

Dari hasil peringkat teratas terdapat peringkat terakhir yang dapat dijadikan acuan untuk mutasi karyawan ke Divisi lain yaitu IT Office Support atau mutasi ke Branch lain.

Tabel 8. Composite Weight

\begin{tabular}{|c|c|c|}
\hline No & Nama Karyawan & $\begin{array}{c}\text { Composite } \\
\text { Weight }\end{array}$ \\
\hline 1 & Karyawan1 & CW 1 \\
\hline 2 & Karyawan2 & CW 2 \\
\hline 3 & Karyawan3 & CW 3 \\
\hline
\end{tabular}

Dari beberapa karyawan dipilih peringkat teratas dari hasil total Composite Weight, karena dalam kasus ini penulis menginginkan mutasi, maka diambil peringkat terbawah [5].

\section{HASIL DAN PEMBAHASAN}

\section{A. Evaluasi Untuk Karyawan}

Setelah mendapatkan nilai bobot faktor serta nilai evaluasi faktor karyawan, maka akan dihitung evaluasi untuk masaingmasing karyawan. Setiap Karyawan yang akan diseleksi mempunyai sebuah nilai evaluasi bagi ke-7 faktor-faktor yang menjadi pertimbangannya, dan kemudian nilai faktor tersebut dikalikan dengan faktor evaluasi dan dijumlahkan untuk mendapatkan total nilai evaluasi untuk setiap tahapan seleksi. Berikut tabel hasil total evaluasi :

Tabel 9. Evaluasi Karyawan Nanang

\begin{tabular}{|l|r|r|r|r|}
\hline \multicolumn{5}{|c|}{ NANANG } \\
\hline \multicolumn{1}{|c|}{ Faktor } & $\begin{array}{r}\text { Bobot } \\
\text { Faktor }\end{array}$ & Kali & $\begin{array}{r}\text { Evaluasi } \\
\text { Faktor }\end{array}$ & $\begin{array}{c}\text { Bobot } \\
\text { Evaluasi }\end{array}$ \\
\hline Absensi & 0,13 & $\mathrm{x}$ & 8,6 & 1,08 \\
\hline $\begin{array}{l}\text { Mengisi } \\
\text { Joblist }\end{array}$ & 0,13 & $\mathrm{x}$ & 9,1 & 1,14 \\
\hline $\begin{array}{l}\text { Kunjungan Sesuai } \\
\text { RPIT }\end{array}$ & 0,14 & $\mathrm{x}$ & 8,6 & 1,24 \\
\hline Disiplin & 0,16 & $\mathrm{x}$ & 8,6 & 1,40 \\
\hline $\begin{array}{l}\text { Kerjasama } \\
\text { Team }\end{array}$ & 0,14 & $\mathrm{x}$ & 9,1 & 1,31 \\
\hline Inovasi & 0,14 & $\mathrm{x}$ & 8,9 & 1,28 \\
\hline $\begin{array}{l}\text { Komitmen } \\
\text { Perusahaan }\end{array}$ & 0,14 & $\mathrm{x}$ & 8,9 & 1,28 \\
\hline Total & 1,0 & & & 8,71 \\
\hline
\end{tabular}


Tabel 10. Hasil Total Evaluasi

\begin{tabular}{|r|l|c|}
\hline NO & NAMA & Total Bobot Evaluasi \\
\hline 1 & NANANG & 8,71 \\
\hline 2 & HERU & 8,66 \\
\hline 3 & EKKY & 8,09 \\
\hline 4 & WAWAN & 7,7 \\
\hline 5 & RIO & 7,59 \\
\hline 6 & JATI & 7,5 \\
\hline 7 & RIZAL & 7,35 \\
\hline 8 & DEDDY & 6,98 \\
\hline 9 & ERMAN & 6,73 \\
\hline
\end{tabular}

\section{B. Perhitungan AHP}

\section{1) Menghitung Pair Comparation Matrix Kriteria}

Tabel 11. Pair Comparation Matrix Kriteria

\begin{tabular}{|c|c|c|c|c|c|c|c|c|}
\hline \multicolumn{9}{|c|}{ Pair Comparation Matrix } \\
\hline Kriteria & Disiplin & $\begin{array}{l}\text { Kunjungan } \\
\text { Sesuai RPIT }\end{array}$ & $\begin{array}{l}\text { Kerjasama } \\
\text { Team }\end{array}$ & Inovasi & $\begin{array}{l}\text { Komitmen } \\
\text { Perusahaan }\end{array}$ & Absensi & $\begin{array}{l}\text { Mengisi } \\
\text { Joblist }\end{array}$ & $\begin{array}{l}\text { Priority } \\
\text { Vector }\end{array}$ \\
\hline Disiplin & 1,00 & 2,00 & 2,00 & 2,00 & 2,00 & 3,00 & 3,00 & 0,2682 \\
\hline $\begin{array}{l}\text { Kunjungan } \\
\text { Sesuai RPIT }\end{array}$ & 0,50 & 1,00 & 1,00 & 1,00 & 1,00 & 2,00 & 2,00 & 0,1451 \\
\hline Kerjasama Team & 0,50 & 1,00 & 1,00 & 1,00 & 1,00 & 2,00 & 2,00 & 0,1451 \\
\hline Inovasi & 0,50 & 1,00 & 1,00 & 1,00 & 1,00 & 2,00 & 2,00 & 0,1451 \\
\hline $\begin{array}{l}\text { Komitmen } \\
\text { Perusahaan }\end{array}$ & 0,50 & 1,00 & 1,00 & 1,00 & 1,00 & 2,00 & 2,00 & 0,1451 \\
\hline Absensi & 0,33 & 0,50 & 0,50 & 0,50 & 0,50 & 1,00 & 1,00 & 0,0758 \\
\hline Mengisi Joblist & 0,33 & 0,50 & 0,50 & 0,50 & 0,50 & 1,00 & 1,00 & 0,0758 \\
\hline Jumlah & 3,6667 & 7,0000 & 7,0000 & 7,0000 & 7,0000 & 13,0000 & 13,0000 & 1,0000 \\
\hline \multicolumn{8}{|c|}{ Principle Eigen Value } & 7,0155 \\
\hline \multicolumn{8}{|l|}{ Consistency Index } & 0,0026 \\
\hline \multicolumn{8}{|l|}{ Consistency Ratio } & $0,2 \%$ \\
\hline
\end{tabular}

\section{Menghitung Overall Composite Weight}

Tabel 12. Overall Composite Weight

\begin{tabular}{|l|c|c|c|c|c|c|c|c|c|c|}
\multirow{2}{*}{ Overall Composite Weight } & Weight & HERU & NANANG & EKKY & RIO & WAWAN & JATI & RIZAL & DEDDY & ERMAN \\
\hline Disiplin & 0,2682 & 0,2464 & 0,2464 & 0,1630 & 0,0429 & 0,1135 & 0,0358 & 0,0499 & 0,0765 & 0,0254 \\
\hline Kunjungan Sesuai RPIT & 0,1451 & 0,1829 & 0,2533 & 0,1976 & 0,0471 & 0,1445 & 0,0403 & 0,0471 & 0,0605 & 0,0267 \\
\hline Kerjasama Team & 0,1451 & 0,1897 & 0,2483 & 0,1755 & 0,1104 & 0,0913 & 0,0767 & 0,0496 & 0,0340 & 0,0245 \\
\hline Inovasi & 0,1451 & 0,3041 & 0,2138 & 0,1471 & 0,0798 & 0,0798 & 0,0737 & 0,0469 & 0,0317 & 0,0231 \\
\hline Komitmen Perusahaan & 0,1451 & 0,3041 & 0,2146 & 0,1492 & 0,0668 & 0,0668 & 0,1017 & 0,0442 & 0,0303 & 0,0223 \\
\hline Absensi & 0,0758 & 0,2198 & 0,3092 & 0,1516 & 0,0441 & 0,1076 & 0,0354 & 0,0511 & 0,0563 & 0,0249 \\
\hline Mengisi Joblist & 0,0758 & 0,1924 & 0,2513 & 0,1782 & 0,0926 & 0,0926 & 0,0834 & 0,0380 & 0,0262 & 0,0452 \\
\hline Composite Weight & & 0,2396 & 0,2435 & 0,1658 & 0,0660 & 0,1011 & 0,0610 & 0,0474 & 0,0495 & 0,0262 \\
\hline
\end{tabular}


Dari 9 orang karyawan dipilih 6 peringkat teratas dari hasil total bobot evaluasi, karena dalam kasus ini penulis menginginkan mutasi, maka diambil 3 peringkat terbawah.

Tabel 13. Peringkat Composite Weight

\begin{tabular}{|r|l|r|}
\hline No & Nama Karyawan & Composite Weight \\
\hline 1 & NANANG & 0,2435 \\
\hline 2 & HERU & 0,2396 \\
\hline 3 & EKKY & 0,1658 \\
\hline 4 & WAWAN & 0,1011 \\
\hline 5 & RIO & 0,0660 \\
\hline 6 & JATI & 0,0610 \\
\hline 7 & DEDDY & 0,0495 \\
\hline 8 & RIZAL & 0,0474 \\
\hline 9 & ERMAN & 0,0262 \\
\hline
\end{tabular}

Berikut tabel perbandingan hasil dari metode MFEP dengan AHP

Tabel 14. Perbandingan hasil metode MFEP dengan AHP

\begin{tabular}{|l|c|c|c|c|c|c|c|c|c|c|}
\cline { 2 - 14 } \multicolumn{1}{c|}{} & \multicolumn{10}{c|}{} \\
\cline { 2 - 13 } \multicolumn{1}{c|}{} & Nanang & Ekky & Heru & Jati & Rizal & Wawan & Erman & Rio & Deddy & $\%$ Kecocokan \\
\hline MFEP & 1 & 3 & 2 & 6 & 7 & 4 & 9 & 5 & 8 & $100 \%$ \\
\hline AHP & 1 & 3 & 2 & 6 & 8 & 4 & 9 & 5 & 7 & $77,78 \%$ \\
\hline MANAGER & 1 & 3 & 2 & 6 & 7 & 4 & 9 & 5 & 8 & \\
\hline PRIORITAS MFEP & TM & TM & TM & TM & M & TM & M & TM & M & $100 \%$ \\
\hline PRIORITAS AHP & TM & TM & TM & TM & M & TM & M & TM & M & $100 \%$ \\
\hline PRIORITAS MANAGER & TM & TM & TM & TM & M & TM & M & TM & M & \\
\hline
\end{tabular}

Ket

M : Mutasi

TM : Tidak Mutasi

Tabel 15. Average Kecocokan

\begin{tabular}{|l|l|c|}
\cline { 2 - 2 } \multicolumn{1}{c|}{} & $\%$ Kecocokan & \%Average \\
\hline MFEP & $100 \%$ & $100 \%$ \\
\hline PRIORITAS MFEP & $100 \%$ & \\
\hline AHP & $77,78 \%$ & $88,89 \%$ \\
\hline PRIORITAS AHP & $100 \%$ & \\
\hline
\end{tabular}

Dari tabel diatas dapat dilihat persentase keputusan kecocokan peringkat keputusan Manager dengan metode MFEP sebesar 100 $\%$ dan kecocokan keputusan Manager dengan metode AHP sebesar 77,78 \%, terlihat persentase keputusan kecocokan peringkat Manager dengan MFEP lebih besar dibandingkan kecocokan peringkat Manager dengan AHP, tetapi kecocokan prioritas keputusan Manager dengan prioritas MFEP dengan menentukan 3 peringkat terbawah yang akan dimutasi sebesar $100 \%$ dan kecocokan prioritas keputusan Manager dengan prioritas AHP dengan menentukan 3 peringkat terbawah yang akan dimutasi sebesar $100 \%$, Maka average kecocokan metode MFEP $100 \%$ sedangkan metode AHP 88,89\%. Penulis menyimpulkan metode MFEP lah yang lebih baik atau lebih cocok digunakan pada Mutasi Karyawan. 


\section{PENUTUP}

Berdasarkan hasil penelitian terhadap Perbandingan Kinerja Multifactor Evaluation Process (MFEP) Dengan Analytic Hierarchy Process (AHP) Dalam Menentukan Mutasi Karyawan, maka dapat diambil kesimpulan "Dengan average kecocokan metode MFEP $100 \%$ sedangkan metode AHP $88,89 \%$. Penulis menyimpulkan metode MFEP lah yang lebih baik atau lebih cocok digunakan pada Mutasi Karyawan”.

\section{REFERENSI}

[1] Kusrini, M.Kom. 2007. Konsep dan Aplikasi

Sistem Pendukung Keputusan. Andi, Yogyakarta.

[2] Render, B dan Stair,M.R,Jr., 2002, Quantitative Analysys for Management, 7th Edition: Prentice Hall.

[3] Marimin, 2004. Teknik dan Aplikasi Pengambilan Keputusan Kriteria Majemuk.Grasindo, Jakarta.

[4] Budiarti, Sri. 2015. "Sistem Informasi Mutasi Pegawai Pada Rumah Sakit Umum Daerah Tugurejo Semarang". Nopember: 1-8.

[5] Novian, Dian. 2010. "Sistem Pendukung Keputusan Mutasi, Enumerasi Dan Promosi Pegawai Menggunakan Metode AHP (analytic hierarchy process)". Media Elektrik Vol. 5, No. 2, Desember: 1-6.

[6] Sari, Nopita. 2015. "Sistem Penentuan Mutasi Pegawai Berdasarkan Metode Multifactor Evaluaton Process". Biltek Vol. 4, No. 018, Januari: 1-6. 